\title{
The Collateral Effect of Antibiotic on Gut Microbiome of Human and their Integrative Role in Human Disease
}

\author{
Heba N Gad EL-Hak ${ }^{1}$, Abdel Raouf A Moustafa ${ }^{2}$ and Samira R. Mansour ${ }^{2 *}$ \\ ${ }^{1}$ Department of Zoology, Suez Canal University, Egypt \\ ${ }^{2}$ Department of Botany, Suez Canal University, Egypt
}

Submission: August 21, 2018; Published: September 05, 2018

"Corresponding author: Samira R. Mansour, Professor of Microbiology, Botany Department, Faculty of Science, Suez Canal University, Ismailia, Egypt, Tel: +201003686076, Fax: +20 643230416; Email: samirarmansour@hotmail.com/samira_ibrahim@science.suez.edu.eg

\begin{abstract}
Antibiotic is a type of antimicrobial drug used for treating and preventing any infection caused by pathogenic bacteria. The widely accepted use of antibiotics has saved millions of human lives all over the world; however, they highly influenced the human microbiome. Human microbiome performs an array of important functions that help us to survive and keep away dangerous disease. Mounting evidence shows that antibiotics alter the constituent of this microbiome and influence the function of the immune system, our ability to resist infection, and our capacity for processing food. Therefore, it is now more important than ever to revisit how we use antibiotics. This review focused on some collateral effects and problems associated with antibiotic use on human gut microbiome. Evidence of histological alternation of intestinal epithelia was considered.
\end{abstract}

Keywords: Antibiotic; Antimicrobial drug; Human microbiome; Immune system; Infection

\section{Introduction}

\section{Importance of antibiotic}

The word antibiotic is derived from the ancient Greek word "antibiotiká which is a type of antimicrobial medicine used for treatment and prevention of bacterial infection [1]. Antibiotics are powerful drug that fight certain diseases caused by bacterial pathogens. They may either destroy or inhibit the growth of these pathogens. Antibiotics are among the most frequently prescribed medications in modern medicine. Common illnesses caused by bacteria are urinary tract infections, strep throat, and some pneumonia; however some common infection can be occurred in gastrointestinal tract (GI) which include oral cavity, esophagus, stomach and intestines and ended at the anus.

There are typically over 70 different types of bacteria in the mouth and most of them occur naturally [2]. Most of these bacterial species appear to be harmless when it comes to our health. Others, known as probiotics, are beneficial bacteria that aid in the digestion of foods. Other bacteria are essential to protect our teeth and gums. However, there are some bacteria cause tooth decay and gum disease. There are, however, bacteria that can contribute to dental decay and periodontal (gum) disease in particular [3]. Esophagus, the second part of GI, is also exposed to all bacterial types including the pathogenic one that exist in the mouth during food swelling or drinking any liquid.

Bacterial infection of stomach and intestine, the major part of GI, is known as bacterial gastroenteritis [4] which can result from poor hygiene. Infection can also occur after close contact with animals or consuming food or water contaminated with bacteria (or the toxic substances bacteria produce). Bacterial infection causes inflammation in stomach and intestines which lead to complicated symptoms like vomiting, severe abdominal cramps, and diarrhea. Most likely to get gastroenteritis by consuming food or water contaminated with harmful bacteria (such as salmonella, Campylobacter, Shigella, Yersinia enterocolitica and Bacillus species including E. coli). Antibiotics are usually reserved for the most severe cases which they help to eliminate most of pathogens and symptoms [5].

In healthy individuals, the microbiome (microbial community) and host have a mutualistic relationship in which both partners benefit; however, pathogens may invade and cause disease under certain conditions. In general, antibiotics can protect human life; they also relieve symptoms resulted from bacterial infections and help us to recover faster. Therefore, the develop- 


\section{Advanced Research in Gastroenterology \& Hepatology}

ment antibiotics were one of the great discoveries in modern medicine. Although, antibiotics fight bacterial pathogens and can cure life-threatening infectious diseases, improper use can cause disaster. Thus, antibiotic is considered as bilateral tool since they have side effects on human health.

\section{Problems associated with antibiotic use}

Many sides effects are associated with prolong medication of antibiotics; beside symptoms of vomiting, severe abdominal cramps, and diarrhea; altering in gut microbiome and develop resistant pathogens to the antibiotics are considered the most important issues that facing the world today. Because resistance has become more common, many diseases cannot be treated as well as they could be in the past and sever health complication can be occurred. To overcome the resistant problem of bacterial pathogens to antibiotics, development and search for new antibiotic trades is considered and becomes a targeting issue nowadays.

In healthy individuals, the microbiome (microbial community) and host have a mutualistic relationship in which both partners benefit; however, pathogens may invade and cause disease under certain conditions. For gut microbiome, their composition is consistent since no interference occurred [6]. This consistent composition can be rapidly altered by exposure to antibiotics. Alternation of microbiome composition has two possible ways to affect human health; direct way with potential immediate effects and indirectly through an affect in a long term on human health [7]. This alternation may lead to the selection of resistant opportunistic pathogens that can cause acute disease. The mutualistic microbes in the human body play a major role in many physiological processes, interact and participate in the regulation of immune and metabolic homeostasis [7]. Therefore, antibiotic exposure can alter much basic physiological equilibrium and consequently boost long-term disease.

Altering the gut microbiome; not only destroying harmful bacteria that are causing infection to different parts of gastrointestinal organs, depending on bacterial pathogens, but also on mutualistic microbes that are beneficial to the host and cannot survive without them [7]. These beneficial microbes play a considerable role in physiological functions that perform live to its host. Further function of gut microbiome is boosting the immune system and help to compete pathogens. Disturbances of gut microbiome, due to uses of antibiotics for long period/ over dose/ improper uses may lead to sever complication in human health which can be represented by: interferes with digestion; linked to food intolerances; increased oxidative stress and defective turnover of mitochondrial protein that lead to damaging of mitochondria (the energy center of every cell in the body) and causing inappropriate cell death [8,9]; linked to auto-immune diseases and other dysfunctions; linked to depression and anxiety; drives stress; physical and emotional; linked to obesity and disrupts glucose metabolism. Alternation of gut microbiome may play a role on the development of some diseases such as malnutrition, obesity, diabetes, and Clostridium difficile infection [10].
Gut microbiome also prevent formation of new function of a protein which is responsible for a disease named "inflammatory bowel disease" (IBD) and regulates pro- and anti-inflammatory cells. The mechanism of prevention was studied and revealed that a protein expressed by gut bacteria called "Bacteroides" works to prevent IBD by rapidly recruiting white blood cells to kill a cell of the immune system that is responsible for orchestrating IBD [11]. Therefore, dysbiosis of the gut bacteria communities can cause many chronic diseases, and may involve in other diseases like obesity, cancer, and autism. Accordingly, keeping normal composition of gut microbiome is important issue for human health.

Alternation of gut microbiome, caused by antibiotic intake, also has highly effect on histology of stomach and small intestine structures. Antibiotic-microbiome disturbance leads to flourishment of opportunistic bacteria that may induce gut injury due to septic or endotoxic shock. In sequence, this may end with intestinal epithelial necrosis/apoptosis. The concept of gut mucosal damage may be explained due to the existence of the hypoxic and ischemic conditions of gut after bacterial infection [12]. Another alternation, of histological intestinal epithelia, is loosen in the tighten junction between villi that facilitate the colonization of pathogenic bacteria, passing of harmful cells, increase their toxin and more challenge for necrosis will occur. In patient who are unable to tolerate enteral feedings, especially those with intestinal failure caused by short bowel syndrome, intestinal atresia, and other gastrointestinal malformations, induced total parenteral nutrition may considered as a major source for the loss of intestinal epithelial barrier function. This may cause the penetration of luminal endotoxins or bacteria into the liver, leading to parenteral nutrition-associated liver disease [13].

\section{Conclusion}

Alternation of gut microbiome, caused by antibiotic intake, has highly effect on human health and increased the risk for gastrointestinal diseases. Among these diseases are those linked to auto-immune diseases and other dysfunctions, dysfunction of intestinal epithelium barrier, linked to depression and anxiety, interconnected to obesity and disrupts glucose metabolism. Altering in gut microbiome can also develop resistant pathogens to the antibiotics which is considered the most important issue that facing the world today. Wise use of antibiotic, especially with infant and childhood, is recommended.

\section{References}

1. Francino MP (2016) Antibiotics and the Human Gut Microbiome: Dysbioses and Accumulation of Resistances. Front Microbiol 6: 1-11.

2. Strom BL, Abrutyn E, Berlin JA, Kinman JL, Feldman RS, et al. (1998) Dental and cardiac risk factors for infective endocarditis: a populationbased, case-control study. Ann Intern Med 129(10): 761-769.

3. Angelillo IF, Nobile CG, Pavia M, De Fazio P, Puca M, et al. (1995) Dental health and treatment needs in institutionalized psychiatric patients in Italy. Community Dent Oral Epidemiol 23(6): 360-364.

4. Gastrointestinal Infections and Diarrhea. 
5. Fedorowicz Zbys, Jagannath Vanitha A, Carter Ben (2011) Antiemetics for reducing vomiting related to acute gastroenteritis in children and adolescents. Cochrane Database Syst Rev (9): CD005506.

6. (2012) Structure, function and diversity of the healthy human microbiome. Nature 486(7402): 207-214.

7. Cox LM, Yamanishi S, Sohn J, Alekseyenko AV, Leung JM, et al. (2014) Altering the intestinal microbiota during a critical developmental window has lasting metabolic consequences. Cell 158(4): 705-721.

8. James AM, Murphy MP (2002) How mitochondrial damage affects cell function. J Biomed Sci 9(6 Pt 1): 475-487.

9. Schwartz S, Friedberg I, Ivanov IV, Davidson LA, Goldsby JS, et al. (2012) Metagenomic study of diet-dependent interaction between gut microbiota and host in infants reveals differences in immune response. Genome Biol 13(4): 32.
10. Yu-Jie Zhang, Sha Li, Ren-You Gan, Tong Zhou, Dong-Ping Xu, et al. (2015) Impacts of Gut Bacteria on Human Health and Diseases. Int J Mol Sci 16(4): 7493-7519.

11. Genevieve J (2017) Study reveals connection between microbiome and autoimmune disorders.

12. Williams JM, Duckworth CA, Burkitt MD, Watson AJM, Campbell BJ, et al. (2014) Epithelial Cell Shedding and Barrier Function: A Matter of Life and Death at the Small Intestinal Villus Tip. Vet Pathol 52(3): 445455 .

13. Xiao YT, Yan WH, Cao Y, Yan JK, Cai W (2017) P38 MAPK pharmacological inhibitor SB203580 alleviates total parenteral nutrition-induced loss of intestinal barrier function but promotes hepatocyte lipoapoptosis. Cell Physiol Biochem 41(2): 623-634.

\section{Your next submission with JuniperPublishers will reach you the below assets}

- Quality Editorial service

- Swift Peer Review

- Reprints availability

- E-prints Service

- Manuscript Podcast for convenient understanding

- Global attainment for your research

- Manuscript accessibility in different formats

( Pdf, E-pub, Full Text, audio)

- Unceasing customer service

Track the below URL for one-step submission https://juniperpublishers.com/online-submission.php 